\title{
Milk composition and flavor under different feeding systems: A survey of dairy farms
}

\author{
M. Yayota, ${ }^{1}$ M. Tsukamoto, Y. Yamada, and S. Ohtani \\ Faculty of Applied Biological Sciences, Gifu University, Gifu 501-1193, Japan
}

\begin{abstract}
Understanding the influence of regional dietary factors on the flavors of milk and dairy products will provide consumers with more options and promote the conservation of regional resources and the original terroir. The objective of this study was to evaluate the influence of regional differences in feeding systems on the composition, fatty acid content, and flavor of pasteurized milk at the farm level. Nine dairy farms using grass silage (GS), 6 farms using maize silage (MS), and 4 farms using by-products (BP) as the characteristic feed components were chosen for this survey. Fresh milk was sampled once per month from September 2008 to February 2009 at each dairy farm. The percentages of GS, MS, and BP (soybean curd residue or brewer's grain) in the feed were $32.4,22.1$, and $15.1 \%$, respectively. The milk fat, protein, and lactose contents did not differ among the milks from farms with different feeding systems. Fatty acids with chain lengths of less than C16 and saturated fatty acids were present at higher concentrations in the milks from the GS and MS farms than in the milk from the BP farms; conversely, fatty acids with chain lengths greater than $\mathrm{C} 18$ and unsaturated fatty acids (UFA), including mono- (MUFA) and polyunsaturated fatty acids (PUFA), were present at higher concentrations in the milks from the BP farms than in the milks from the GS farms. No significant differences were detected in milk flavor, evaluated as sweetness, body, texture, aftertaste, and palatability, between the milks from the farms with different feeding systems. The proportion of BP in the cow's diet was positively correlated with the concentrations of fatty acids with chain lengths greater than $\mathrm{C} 18$ and with UFA, MUFA, and PUFA. In contrast, the proportion of GS in the diet was positively associated with the levels of milk fat, protein, fatty acids with chain lengths less than C16, and SFA. The MUFA, PUFA, UFA, and fatty acids with chain lengths greater than C18 were not associated with any of the milk flavors. These results suggest the regional differences in feeding
\end{abstract}

Received July 19, 2012.

Accepted April 29, 2013.

${ }^{1}$ Corresponding author: yayo@gifu-u.ac.jp systems contribute to the differences in the fatty acid compositions of milk at the farm level. However, these differences do not influence the flavor of pasteurized milk. Thus, more specific feed profiles will be required to provide a specific regional flavor to pasteurized milk. Key words: feeding system, milk fatty acid, milk flavor, regional resource

\section{INTRODUCTION}

Consumers prefer foods, including milk and dairy products, which have favorable sensory qualities. Although the sensory qualities of milk and dairy products are affected by many factors (Martin et al., 2005b), the acceptance of and preference for milk as a beverage are influenced by its flavor over all other attributes (Thomas, 1981). The flavor of milk depends on animal management factors, such as breed, lactation stage, and diet, as well as processing factors, such as pasteurization technique. Among animal management factors, the diet is considered the primary and most sensitive factor for creating a specific flavor for milk and dairy products (Martin et al., 2005a, b). Recently, the linkage between specific flavors and dietary factors has taken on a special importance for products with a protected designation of origin or a protected geographical indication in European Union countries (Martin et al., 2005a,b) and for local brands of milk and dairy products in Japan; these designations conserve regional resources and economies. Because the production and procurement of basic feed sources are largely constrained by regional climate, soil, flora, and economic requirements, a region-specific flavor may be imparted to the milk and dairy products. Studies have examined how forage type and botanical diversity affect the flavors of milk and dairy products, mainly cheeses, in some EU countries (Carpino et al., 2004a,b; Martin et al., 2005b; Croissant et al., 2007); however, these influences must be confirmed in other countries and regions because the forage type and botanical diversity, as well as the sensitivity and preferences for milk and dairy products (Urbach, 1990), differ between countries.

Although the flavors of milk and other dairy products are affected by various chemical compounds, milk 
fats and FA may play a role (Urbach, 1990; Chen et al., 2004). It is known that the degree of unsaturation, the chain length of FA, and the position of FA on the triacylglycerol group influence the melting point of the fats and, thus, alter the texture and taste of the milk. In contrast, the degree of unsaturation also affects the presence of off-flavors in dairy products by changing the oxidation rate (Thomas, 1981). Additionally, certain FA may be precursors of compounds that produce specific dairy product aromas (Urbach, 1990). Although these flavor-generating compounds are generally produced by the heating or processing of milk fats and FA, the chemical reactions may be associated with substantial changes in the FA profile of milk.

Numerous studies have examined the effects of forage type and supplementary lipids on the FA composition of milk. Chilliard et al. (2000) and Chilliard and Ferlay (2004) found that several lipid supplements, such as rapeseed, linseed, and fresh grass rich in PUFA, increase the amounts of MUFA, PUFA, and conjugated linoleic acid in milk. Further, the influence of the forage type (Bugaud et al., 2001; Martin et al., 2005a,b) and supplementary lipids (Baer et al., 2001) on the flavors of milk and dairy products have also been studied in detail. These studies revealed that the feed type modified the physicochemical and sensory properties of the milk and dairy products. However, most of these studies were conducted under well-controlled conditions, and relatively little is known about how the sensory qualities of milk are related to the feeding regimens used under real farm conditions, even though this relationship is potentially significant for dairy farms and the dairy industry. Moreover, relationships among the type of feed, FA composition of the milk, and milk flavor should be reconsidered in terms of regional specificity and the origins of milk and dairy products. The FA composition of milk was found to differ among regions (Palmquist et al., 1993), providing different flavors and flavor potentials to the milk and dairy products (Urbach, 1990).

In Japan and some other countries, 3 distinctive feeding systems are used in dairy farming: (1) a grass silagebased feeding system, which is widespread in grassland farming areas; (2) a maize silage-based feeding system, which is used in relatively fertile farming areas; and (3) a by-product-based farming system, which is a suburban dairy farming method that uses industrial by-products. These differences in feeding systems may result in different milk compositions, particularly with respect to FA, and may create different and specific flavors in milk.

The objective of this study was to evaluate the influence of regional differences in feeding systems on the composition of milk and milk FA and, thus, the flavor of the milk at the farm level. Understanding the origin of specific regional flavors in milk and dairy products will promote the development of a targeted marketing strategy by the dairy industry and farmers, provide consumers with greater options for milk flavor, and help conserve regional feed resources and the original terroir.

\section{MATERIALS AND METHODS}

\section{Survey of Commercial Dairy Farms}

This survey was conducted from September 2008 to February 2009 in the Gifu prefecture of central Japan $\left(136^{\circ} 16^{\prime} 35^{\prime \prime}\right.$ to $137^{\circ} 39^{\prime} 11^{\prime \prime} \mathrm{E}, 35^{\circ} 08^{\prime} 02^{\prime \prime}$ to $\left.35^{\circ} 39^{\prime} 11^{\prime \prime} \mathrm{N}\right)$. Nineteen commercial dairy farms were chosen based on their feeding systems. All of the herds consisted primarily of Holstein cows; however, 3 of the herds also included Jersey cows (9.7\% of the herd on the average), and 1 herd included Brown Swiss cows (5.3\% of the herd). Of these 19 dairy farms, 9 were located on the Hirugano highland and used grass silage (GS) as the main type of forage. Six farms were located in upland cropping areas and used maize silage (MS) as the primary type of feed. The remaining 4 farms were located in a suburban area and used feed containing by-products $(\mathbf{B P})$ as the characteristic feed. The GS was a mixture containing primarily reed canarygrass (Phalaris arundinacea L.). The BP were either soybean curd residue or brewer's grains. According to the standard tables of feed composition in Japan (NARO, 2009), soybean curd residue and brewer's grain have slightly different crude fat contents (12.6 vs. $9.3 \%$ DM basis, respectively) and CP contents (27.8 vs. $25.5 \%$ DM basis, respectively); likewise, they have a large difference in NDF content (34.2 vs. $62.5 \mathrm{DM}$ basis, respectively). Further, both BP have approximately the same FA profile, except for palmitic acid (C16:0; Peñalvo et al., 2004; Miyazawa et al., 2007). Although several differences exist in the chemical and FA compositions of the soybean curd residue and brewer's grain, we grouped these feeds together in terms of regionally available feeds. The daily feed regimen provided at each farm was investigated during mid-November 2008 (Table 1). All the farms used a confinement feeding system and used each characteristic feed year-round. Most of the feeds, other than GS and MS, were purchased throughout the year. Therefore, no substantial changes in the feed regimen occurred during the research period. We interviewed each farmer to determine the type of feed and average feeding amount for lactating cows during the winter season. Samples of GS, MS, and BP from the respective farms were collected, and the DM contents of these feeds were determined according to method 930.15 of AOAC 
(AOAC International, 2006). The DM contents of other feeds were estimated from the standard tables of feed composition in Japan (NARO, 2009). The number of lactating cows and the total milk yield were taken from the records of the local dairy company, and individual milk yields were calculated from these 2 values.

\section{Milk Sampling}

Fresh milk was sampled once per month from September 2008 to February 2009 at each dairy farm. After the morning milking, fresh milk, which was a composite of evening and morning milk in a bulk tank, was stirred for 1 min, after which a 500-mL sample was taken in a polyethylene bottle. The bottle was immediately placed in a cold box and then taken to the laboratory at Gifu University. Half of the sample was subjected to milk fat, protein, lactose, and SNF analysis. The sample was kept at $4^{\circ} \mathrm{C}$ and analyzed immediately. The remaining sample was used to determine the FA composition and was kept below $-30^{\circ} \mathrm{C}$ in a freezer until analysis.

\section{Analyses of Milk and Milk FA Composition}

The milk fat, protein, and lactose concentrations were determined using the Gerber method (AOAC International, 2006; method 2000.18), the Kjeldahl method (AOAC International, 2006; method 991.20), and the phenol-sulfuric acid method (Dubois et al., 1956; Marier and Boulet, 1959), respectively. The SNF level was measured according to the AOAC method (AOAC International, 2006; method 990.21).

The FA composition of the milk was determined according to the method used by Feng et al. (2004). Frozen milk was thawed in a water bath at $32^{\circ} \mathrm{C}$. A 20 -mL sample of milk was centrifuged at $17,800 \times g$ for $30 \mathrm{~min}$ at $4^{\circ} \mathrm{C}$. Approximately $1 \mathrm{~g}$ of the fat-cake layer was removed, placed into a microtube and left at room

Table 1. The number of lactating cows, individual milk yield, and feeding regimen of the investigated dairy farms

\begin{tabular}{|c|c|c|c|}
\hline \multirow[b]{2}{*}{ Item } & \multicolumn{3}{|c|}{ Feeding system ${ }^{2}$} \\
\hline & GS & MS & $\mathrm{BP}$ \\
\hline No. of farms & 9 & 6 & 4 \\
\hline No. of lactating cows & $20.4 \pm 11.5$ & $44.0 \pm 37.6$ & $37.0 \pm 6.6$ \\
\hline Milk yield ( $\mathrm{kg} /$ cow per day) & $23.1 \pm 3.5$ & $23.6 \pm 5.3$ & $23.2 \pm 1.6$ \\
\hline \multicolumn{4}{|c|}{ Feed offered ( $\mathrm{kg}$ of $\mathrm{DM} / \mathrm{cow}$ per day) } \\
\hline Grass silage $^{3}$ & $7.1 \pm 4.0^{\mathrm{a}}$ & $0.4 \pm 1.1^{\mathrm{b}}$ & $0.9 \pm 1.2^{\mathrm{b}}$ \\
\hline Maize silage & $0 \pm 0^{\mathrm{b}}$ & $4.0 \pm 1.7^{\mathrm{a}}$ & $0 \pm 0^{\mathrm{b}}$ \\
\hline By-products ${ }^{4}$ & $0 \pm 0^{\mathrm{b}}$ & $0.2 \pm 0.5^{\mathrm{b}}$ & $2.2 \pm 0.4^{\mathrm{a}}$ \\
\hline $\mathrm{Hay}^{5}$ & $1.6 \pm 2.3$ & $3.4 \pm 2.3$ & $4.1 \pm 3.0$ \\
\hline Beet pulp & $1.5 \pm 0.9$ & $0.8 \pm 0.7$ & $1.4 \pm 0.2$ \\
\hline Alfalfa hay cube & $1.4 \pm 0.7$ & $1.2 \pm 0.7$ & $1.1 \pm 0.9$ \\
\hline Formula feed ${ }^{6}$ & $9.3 \pm 1.3^{\mathrm{a}}$ & $7.6 \pm 4.0^{\mathrm{ab}}$ & $3.6 \pm 3.5^{\mathrm{b}}$ \\
\hline Other concentrates $^{7}$ & $0.4 \pm 0.8$ & $1.4 \pm 1.7$ & $2.2 \pm 2.1$ \\
\hline Total & $21.3 \pm 4.6$ & $19.1 \pm 3.3$ & $15.5 \pm 3.3$ \\
\hline \multicolumn{4}{|l|}{ Ratio in the diet (\%) } \\
\hline Characteristic feed ${ }^{8}$ & $32.4 \pm 13.1$ & $22.1 \pm 11.8$ & $15.1 \pm 5.6$ \\
\hline Forage & $46.6 \pm 7.6$ & $49.5 \pm 14.9$ & $37.6 \pm 13.1$ \\
\hline Formula feed & $44.9 \pm 7.9^{\mathrm{a}}$ & $38.3 \pm 15.2^{\mathrm{ab}}$ & $21.0 \pm 18.5^{\mathrm{b}}$ \\
\hline Total concentrates ${ }^{9}$ & $53.4 \pm 7.6$ & $50.5 \pm 14.9$ & $62.4 \pm 13.1$ \\
\hline
\end{tabular}

${ }^{\mathrm{a}, \mathrm{b}}$ Means from the same row but with different superscripts differ $(P<0.05$; Tukey honestly significant difference).

${ }^{1}$ Values are mean $\pm \mathrm{SD}$.

${ }^{2} \mathrm{GS}=$ grass silage; $\mathrm{MS}=$ maize silage; $\mathrm{BP}=$ by-products.

${ }^{3}$ Grass silage was made from reed canarygrass.

${ }^{4}$ By-products were either soybean curd residue or brewer's grains.

${ }^{5}$ Hay was commodity or a mixture of alfalfa hay, bermudagrass hay, Italian ryegrass hay, Kleingrass hay, oats hay, reed canarygrass hay, Sudangrass hay, or timothy hay.

${ }^{6}$ Commercial formula feed was generally composed of approximately $50 \%$ grain (heat-treated maize, maize, flour, heat-treated soybeans), $20 \%$ chaff and bran (corn gluten feed, wheat bran, rice bran), $20 \%$ oilseed meal (soybean meal, rapeseed meal, corn jam meal, corn gluten meal), and $10 \%$ other components (cottonseed, molasses, calcium carbonate, sodium chloride).

${ }^{7}$ Other concentrates were commodity or a mixture of barley, cottonseed meal, maize, soybean, soybean meal, wheat, and wheat bran.

${ }^{8}$ Characteristic feed was grass silage, maize silage, or by-products.

${ }^{9}$ Sum of formula feed and other concentrates. 
temperature until the fat cake melted. The melted fat was then centrifuged at $19,300 \times g$ for $20 \mathrm{~min}$ at room temperature, and the top layer of lipids was collected. A $40-\mu \mathrm{L}$ sample of the separated lipids was transesterified by mixing with $40 \mu \mathrm{L}$ of methyl acetate, $40 \mu \mathrm{L}$ of tridecanoic acid (internal standard), $40 \mu \mathrm{L}$ of nonadecanoic acid, and $2 \mathrm{~mL}$ of hexane, followed by the addition of $40 \mu \mathrm{L}$ of the methylating agent $(1.75 \mathrm{~mL}$ of methanol $+5.4 \mathrm{~mol} / \mathrm{L}$ of sodium methoxide). The mixture was allowed to react for $10 \mathrm{~min}$. Then, $60 \mu \mathrm{L}$ of stop solution ( $1 \mathrm{~g}$ of oxalic acid per $30 \mathrm{~mL}$ of diethyl ether) was added, and the sample was centrifuged at $2,400 \times g$ for $5 \mathrm{~min}$ at $5^{\circ} \mathrm{C}$ to obtain the FA methyl esters. The FA compositions were quantified using a gas chromatograph (GC-14A, Shimadzu Co., Kyoto, Japan) equipped with a flame-ionization detector and a 30-m fused silica capillary column (i.d. $0.25 \mathrm{~mm}$, HRSS-10, GL Science, Tokyo, Japan). Helium was used as the carrier gas and hydrogen was used as the fuel gas. The injector and detector temperatures were set to $225^{\circ} \mathrm{C}$. The FA composition of a $2-\mu \mathrm{L}$ sample was determined with a split ratio of 1:35 using the temperature gradient program from Feng et al. (2004). The peaks were identified using authentic standards (GLC-87, GLC-Reference standard, FA methyl esters, $\mathrm{Nu}$-Chek Prep Inc., Elysian, MN). The peak area for each FA was corrected using tridecanoic acid methyl ester as a reference. The amount of $\mathrm{FA}(\mathrm{ng})=$ the peak area of each $\mathrm{FA} \times$ the molecular weight of each $\mathrm{FA} \times$ the content of the tridecanoic acid $\div$ the peak area of tridecanoic acid [1]. The content of FA $(\mathrm{g} / 100 \mathrm{~g})=$ the amount of FA (ng) $\div$ the total amount of FA (ng) $\times$ $100[2]$.

\section{Sensory Testing}

Sensory testing of the milk was conducted using a scorecard judging and grading method. The sensory tests were carried out on December 15 and 16, 2008. Fresh milk samples from 5 GS farms, 6 MS farms, and 4 BP farms were used for sensory assessment. To balance the tasting frequency, 5 farms were randomly chosen from among the 9 GS farms for the sensory assessment. No significant or substantial differences existed in the feeding regimens or milk FA profiles between all the GS farms and the 5 GS farms used for the sensory test (data not shown). Thus, this random selection of farms did not affect the sensory properties of the milk from GS farms. The 500-mL samples of fresh milk were taken from each farm on December 14 and stored at $4^{\circ} \mathrm{C}$ in a refrigerator. The collected milk was then pasteurized $\left(65^{\circ} \mathrm{C}, 30 \mathrm{~min}\right)$ using a water-bath before the sensory test. Twenty-three panelists were chosen from among the students of Gifu University. All panelists were required to score more than $60 \%$ on a taste distinguishing test (Japan Federation of Milk Processors Co-operatives, 2005) conducted before the sensory assessment. Each panelist tasted 8 cups (approximately $10 \mathrm{~mL} / \mathrm{cup}$ ) of pasteurized milk in random order to eliminate order effect, and 12 to 13 panelists assessed the milk from each farm. The evaluation was conducted in double-blind fashion (i.e., neither the panelists nor the researchers knew which milk samples were from the GS, MS, or BP farms) to prevent the outcomes from being influenced by researcher bias. The milk was provided to the panelists at 7 to $10^{\circ} \mathrm{C}$ so that they could evaluate the milk's flavors under normal drinking conditions (Japan Federation of Milk Processors Co-operatives, 2005). The panelists evaluated 5 flavors - sweetness, body, texture, aftertaste, and palatability - on a scale of -2 to 2 (Table 2). Those flavors were selected based on the JIS Z 8144 (Japanese Industrial Standard Committee, 2004). Before the flavor evaluation, all the panelists tasted a commercial ultrahigh temperature-treated milk sample as a standard (i.e., the flavors of the ultrahigh temperature milk were scored as 0 ). The tasting was conducted in a room with an air temperature of 20 to $22^{\circ} \mathrm{C}$ and normal fluorescent lighting.

\section{Statistical Analysis}

Each farm was treated as an experimental unit. The data for the milk yields and feeds were collected on a single occasion, and the differences between the feeding systems were analyzed using the Tukey-HSD test. The differences in milk composition and milk FA composition were analyzed using a mixed ANOVA model that included the feeding system as a fixed factor, the month as a repeated measures factor, the farm as a random factor nested within each feeding system, and an interaction between feeding systems and months. When significance was detected in the mixed ANOVA model, the differences between the feeding systems were analyzed using the Tukey-HSD test. Because the sensory properties of the milk were nonparametric and ordinal, the differences between the feeding systems were analyzed using a Kruskal-Wallis test. In this analysis, each panelist scored only some milk samples; thus, we used the averages of the sensory data from the panelists for each farm. Due to this design limitation, we did not consider a panelist effect in the sensory analyses.

Principal component analysis (PCA) was conducted to evaluate the relationships between the type of feed and the milk composition, including milk FA, and between the milk composition and sensory properties. The milk FA were grouped as FA of $\mathrm{C} 16$ or shorter $(\leq \mathrm{C} 16)$, FA of $\mathrm{C} 18$ or longer $(\geq \mathrm{C} 18)$, total SFA, MUFA, PUFA, and total UFA for the PCA. Thus, 16 variables (6 feed 
Table 2. Definitions and scales for sensory properties used to describe fresh milk

\begin{tabular}{|c|c|}
\hline Item $^{1}$ & Definition and scales \\
\hline Sweetness & $\begin{array}{l}\text { A fundamental taste characteristic of simple sugar. } \\
\text { Low }(-) \rightarrow \text { High }(+) \text {. }\end{array}$ \\
\hline Body (kokumi) & $\begin{array}{l}\text { Degree to which the size or heft of the sample feels heavy or light. } \\
\text { Light }(-) \rightarrow \text { Heavy }(+) \text {. }\end{array}$ \\
\hline Texture & $\begin{array}{l}\text { Degree to which the surface of the samples feels smooth or rough in the mouth. } \\
\text { Rough }(-) \rightarrow \text { Smooth }(+) \text {. }\end{array}$ \\
\hline Aftertaste & $\begin{array}{l}\text { Length of time after swallowing the sample the flavor persists in the mouth. } \\
\text { Short }(-) \rightarrow \text { Long }(+) \text {. }\end{array}$ \\
\hline Palatability & $\begin{array}{l}\text { General characteristics that elicit pleasurable sensation in the mouth. } \\
\text { Poor }(-) \rightarrow \text { Good }(+) \text {. }\end{array}$ \\
\hline
\end{tabular}

variables and 10 milk composition variables) and 15 variables (10 milk composition variables and 5 sensory property variables) were considered in the feed-milk composition PCA and the milk composition-sensory properties PCA, respectively. The data from all the farms $(\mathrm{n}=19)$ and the data from the farms used in the sensory test $(\mathrm{n}=15)$ were used in the first and second PCA, respectively. All variables were standardized to have a mean of 0 and a standard deviation of 1 to calculate the coefficients of correlation between variables. All statistical procedures were conducted using JMP ver. 5 (SAS Institute Inc., Cary, NC).

\section{RESULTS}

\section{Feeding Management in Dairy Farms}

No differences were observed in the individual milk yields between the feeding systems (Table 1 ). The cows were provided with $7.1,4.0$, and $2.2 \mathrm{~kg}$ of $\mathrm{DM} /$ cow per day of the characteristic feed components (i.e., GS, MS, and BP, respectively). These components contributed $32.4,22.1$, and $15.1 \%$ of the diets in the GS, MS, and BP farms, respectively (Table 1). Almost all of the dairy farms provided hay, beet pulp, alfalfa hay cubes, and commercial formula feed in addition to the characteristic components. Regardless of the farm, the commercial formula feed was generally composed of approximately $50 \%$ grain (heat-treated maize, maize, flour, heat-treated soybeans), $20 \%$ chaff and bran (corn gluten feed, wheat bran, rice bran), $20 \%$ oilseed meal (soybean meal, rapeseed meal, corn jam meal, corn gluten meal), and $10 \%$ other components (cotton seed, molasses, calcium carbonate, sodium chloride). These commercial formula feeds are commonly used on Japanese dairy farms. Although the levels of these feedstuffs differed between the feeding systems, the only substantial difference was observed in the level of formula feed $(P<0.05)$. The ratio for formula feed was higher at the GS farms than that at the BP farms $(P<0.05)$; however, the ratio of total concentrates in the diet did not differ between the farms. In addition, the variability in the feeding management remained consistent in the same feeding system.

\section{Milk Compositions and Milk Flavors in Dairy Farms}

The milk fat, protein, and SNF contents did not differ between the feeding systems (Table 3); however, the lactose contents for the MS and BP farms were significantly higher than that for the GS farms $(P<0.05)$. The feeding system markedly affected the FA composition of the milk (Table 3). Overall, the concentrations $\leq \mathrm{C} 16$ and SFA were higher in the milks from the GS and MS farms than in the milk from the BP farms $(P$ $<0.05)$. Conversely, the concentrations of $\geq \mathrm{C} 18$, UFA, and MUFA were higher in the milk from the BP farms than in the milk from the GS and MS farms $(P<0.05)$. The milk from the BP farms tended to contain more PUFA than the milk from the GS and MS farms $(P=$ 0.079). The FA content of the milk from the MS farms was intermediate between those of the milks from the GS and BP farms. No differences in the milk flavors were detected between the feeding systems due to the large variations in the properties of the milks from each group (Table 4), although the milks from the GS farms appeared to have a slightly heavier body $(P=0.097)$.

\section{Relationships Between Feeding Management, Milk Composition, and Milk Flavors}

The PCA between the feed style and milk composition showed that principal components 1 and 2 accounted for 49.2 and $16.7 \%$ of the variability, respectively (Figure 1). The proportion of $\mathrm{BP}$ in the diet was positively correlated with the contents of $\geq \mathrm{C} 18$, MUFA, PUFA, and UFA. In contrast, both the proportion of GS and the proportion of the formula feed in the diet were positively associated with general milk composition parameters, such as the milk fat and protein contents, and positively associated with the level of $\leq \mathrm{C} 16$ and SFA. Other feeding management parameters, including 
Table 3. Milk composition and FA compositions of pasteurized milk from the different feeding systems of the dairy farms

\begin{tabular}{|c|c|c|c|c|c|}
\hline \multirow[b]{2}{*}{ Item } & \multicolumn{3}{|c|}{ Feeding system ${ }^{1}$} & \multirow{2}{*}{$\begin{array}{l}\text { Pooled } \\
\text { SD }\end{array}$} & \multirow[b]{2}{*}{$P$-value } \\
\hline & GS & MS & $\mathrm{BP}$ & & \\
\hline No. of farms & 9 & 6 & 4 & & \\
\hline \multicolumn{6}{|l|}{ Milk composition (\%) } \\
\hline Fat & 4.09 & 3.91 & 3.91 & 0.16 & 0.470 \\
\hline Protein & 3.27 & 3.25 & 3.11 & 0.10 & 0.209 \\
\hline Lactose & $4.65^{\mathrm{b}}$ & $4.77^{\mathrm{a}}$ & $4.79^{\mathrm{a}}$ & 0.20 & $<0.001$ \\
\hline Solids not fat & 8.83 & 8.86 & 8.57 & 0.15 & 0.220 \\
\hline \multicolumn{6}{|l|}{ Milk FA (g/100 g) } \\
\hline $\mathrm{C} 12: 0$ & $4.31^{\mathrm{a}}$ & $3.92^{\mathrm{ab}}$ & $3.37^{\mathrm{b}}$ & 0.32 & 0.005 \\
\hline $\mathrm{C} 13: 0$ & 0.14 & 0.15 & 0.11 & 0.03 & 0.186 \\
\hline C14:0 & $13.20^{\mathrm{a}}$ & $12.39^{\mathrm{a}}$ & $11.26^{\mathrm{b}}$ & 0.59 & 0.001 \\
\hline $\mathrm{C} 14: 1$ & $1.57^{\mathrm{a}}$ & $1.54^{\mathrm{ab}}$ & $1.34^{\mathrm{b}}$ & 0.09 & 0.031 \\
\hline C15:0 & 1.27 & 1.28 & 1.12 & 0.08 & 0.094 \\
\hline C16:0 & $33.09^{\mathrm{a}}$ & $32.97^{\mathrm{a}}$ & $29.21^{\mathrm{b}}$ & 1.03 & 0.011 \\
\hline $\mathrm{C} 16: 1$ & $1.81^{\mathrm{ab}}$ & $1.94^{\mathrm{a}}$ & $1.51^{\mathrm{b}}$ & 0.09 & 0.044 \\
\hline $\mathrm{C} 16: 1 t$ & 0.17 & 0.17 & 0.15 & 0.01 & 0.258 \\
\hline C17:0 & 0.65 & 0.67 & 0.62 & 0.03 & 0.558 \\
\hline C18:0 & 11.58 & 11.30 & 13.40 & 0.06 & 0.057 \\
\hline $\mathrm{C} 18: 1$ & $25.60^{\mathrm{b}}$ & $26.71^{\mathrm{ab}}$ & $27.85^{\mathrm{a}}$ & 1.29 & 0.012 \\
\hline $\mathrm{C} 18: 1 t$ & $1.19^{\mathrm{b}}$ & $1.15^{\mathrm{b}}$ & $2.66^{\mathrm{a}}$ & 0.35 & 0.001 \\
\hline $\mathrm{C} 18: 2$ & 3.24 & 3.69 & 4.87 & 0.36 & 0.063 \\
\hline $\mathrm{C} 18: 2 t t$ & 0.47 & 0.47 & 0.64 & 0.10 & 0.245 \\
\hline $\mathrm{C} 18: 3$ & 0.54 & 0.49 & 0.65 & 0.06 & 0.332 \\
\hline $\mathrm{C} 19: 0$ & 0.27 & 0.27 & 0.25 & 0.16 & 0.825 \\
\hline C20:0 & 0.30 & 0.31 & 0.40 & 0.13 & 0.578 \\
\hline $\mathrm{C} 20: 1$ & 0.10 & 0.09 & 0.10 & 0.04 & 0.562 \\
\hline $\mathrm{C} 20: 3$ & 0.24 & 0.20 & 0.20 & 0.21 & 0.857 \\
\hline $\mathrm{C} 20: 4$ & 0.20 & 0.26 & 0.25 & 0.05 & 0.239 \\
\hline $\mathrm{C} 22: 0$ & 0.04 & 0.04 & 0.04 & 0.04 & 0.825 \\
\hline$\leq \mathrm{C} 16^{2}$ & $55.57^{\mathrm{a}}$ & $54.35^{\mathrm{a}}$ & $48.08^{\mathrm{b}}$ & 1.81 & 0.004 \\
\hline$\geq \mathrm{C} 18^{3}$ & $43.78^{\mathrm{b}}$ & $44.98^{\mathrm{b}}$ & $51.30^{\mathrm{a}}$ & 1.81 & 0.004 \\
\hline$\overline{\mathrm{SFA}}{ }^{4}$ & $64.86^{\mathrm{a}}$ & $63.30^{\mathrm{a}}$ & $59.79^{\mathrm{b}}$ & 1.38 & 0.002 \\
\hline MUFA $^{5}$ & $30.45^{\mathrm{b}}$ & $31.60^{\mathrm{b}}$ & $33.61^{\mathrm{a}}$ & 1.35 & 0.003 \\
\hline $\mathrm{PUFA}^{6}$ & 4.69 & 6.11 & 6.60 & 0.47 & 0.079 \\
\hline $\mathrm{UFA}^{7}$ & $35.14^{\mathrm{b}}$ & $36.70^{\mathrm{b}}$ & $40.21^{\mathrm{a}}$ & $\begin{array}{l}0.41 \\
1.38\end{array}$ & 0.002 \\
\hline
\end{tabular}

${ }^{\mathrm{a}, \mathrm{b}}$ Means from the same row but with different superscripts differ $(P<0.05$; Tukey honestly significant difference).

${ }^{1} \mathrm{GS}=$ grass silage; $\mathrm{MS}=$ maize silage; $\mathrm{BP}=$ by-products.

${ }^{2}$ Sum of FA shorter than C16:1.

${ }^{3}$ Sum of FA longer than C18:0.

${ }^{4}$ Saturated FA $\Sigma$ C12:0, C13:0, C14:0, C15:0, C16:0, C17:0, C18:0, C19:0, C20:0, and C22:0.

${ }^{5}$ Monounsaturated FA $\Sigma$ C14:1, C16:1, C16:1 $t$, C18:1, C18:1t, and C20:1. $t=$ trans.

${ }^{6}$ Polyunsaturated FA $\Sigma$ C18:2, C18:2t, C18:3, C20:3, and C20:4.

${ }^{7}$ Unsaturated FA $\Sigma$ MUFA and PUFA.

Table 4. The flavors in pasteurized milk from the different feeding systems of the dairy farms ${ }^{1}$

\begin{tabular}{lllll}
\hline & \multicolumn{3}{c}{ Feeding system } \\
\cline { 2 - 4 } Item & \multicolumn{1}{c}{ GS } & \multicolumn{1}{c}{ MS } & \multicolumn{1}{c}{ BP } & P-value \\
\cline { 2 - 4 } & 5 & 6 & 4 & \\
n & $0.50(0.21-1.00)$ & $0.29(0.15-0.72)$ & $0.31(0.12-0.78)$ & 0.759 \\
Sweetness & $0.77(0.59-1.04)$ & $0.48(-0.00-0.69)$ & $0.35(0.20-0.68)$ & 0.097 \\
Texty (kokumi) & $0.31(0.24-0.36)$ & $0.25(0.08-0.36)$ & $0.18(0.08-0.30)$ & 0.385 \\
Aftertaste & $0.25(-1.25-0.39)$ & $0.40(0.11-0.48)$ & $0.28(0.04-0.47)$ & 0.545 \\
Palatability & $0.15(-0.13-0.55)$ & $0.19(-0.10-0.60)$ & $0.28(0.13-0.56)$ & 0.765 \\
\hline
\end{tabular}

${ }^{1}$ The panelists evaluated each flavor on a scale of -2 to 2 ; values are medians with 25 to $75 \%$ quartile point.

${ }^{2} \mathrm{GS}=$ grass silage; $\mathrm{MS}=$ maize silage $; \mathrm{BP}=$ by-products. 


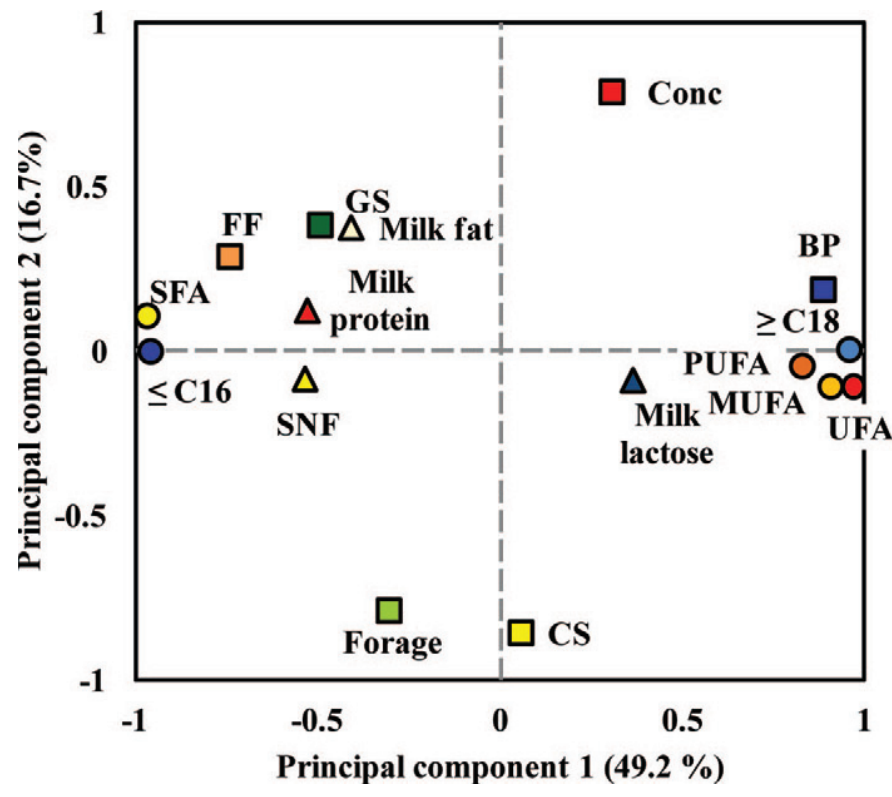

Figure 1. The principal component analysis describing the relationships among feeding management and milk compositions. GS = grass silage; $\mathrm{MS}=$ maize silage $; \mathrm{BP}=$ by-products; $\mathrm{FF}=$ formula feed; $\mathrm{SNF}=$ solids not fat; Conc $=$ concentrates including $\mathrm{FF} ; \leq \mathrm{C} 16$ $=$ sum of FA shorter than $\mathrm{C} 16: 1 ; \geq \mathrm{C} 18=$ sum of FA longer than C18:0; SFA $=\Sigma$ C12:0, C13:0, C14:0, C15:0, C16:0, C17:0, C18:0, C19:0, C20:0, and C22:0; MUFA $=\Sigma$ C14:1, C16:1, C16:1t, C18:1, $\mathrm{C} 18: 1 t$, and $\mathrm{C} 20: 1 ; \mathrm{PUFA}=\Sigma \mathrm{C} 18: 2, \mathrm{C} 18: 2 t, \mathrm{C} 18: 3, \mathrm{C} 20: 3$, and $\mathrm{C} 20: 4$ $\mathrm{UFA}=\Sigma$ MUFA and PUFA. $t=$ trans. Color version available in the online PDF.

the proportions of MS, forage, and concentrates, were not related to any aspects of milk composition.

The PCA of the milk composition and the flavors showed that principal components 1 and 2 accounted for 45.4 and $22.4 \%$ of the variability, respectively (Figure 2). Most of the flavors fell in the first quadrant, and these properties were positively associated with the levels of milk protein, SNF, and lactose rather than the levels of any type of FA. The contents of MUFA, PUFA, UFA, and $\geq \mathrm{C} 18$ were not related to milk flavor.

\section{DISCUSSION}

Although each feeding system can be characterized by the use of GS, MS, or BP, the feeding regimens varied between and within each feeding system. Feeding variation is inevitable on commercial dairy farms; however, the results of this study should be considered to reflect the influences of feedstuffs other than the characteristic feed, such as formula feed and hay, because the characteristic feeds made up, at most, $32 \%$ of the feed on the GS farms, $22 \%$ of the feed on the MS farms, and $15 \%$ of the feed on the BP farms.

The milk compositions did not differ between the feeding systems, except for the amount of lactose. The
PCA showed that milk fat, milk protein, and SNF content were strongly associated, relatively well-associated, and slightly associated, respectively, with the proportion of GS or formula feed in the diet. According to previous reports (Shingfield et al., 2005; Nielsen et al., 2006; Kliem et al., 2008), the milk fat content was higher but the milk protein content was lower in milk from cows that were fed GS than in milk from cows that were fed MS; however, these results have not been consistent (Fitzgerald and Murphy, 1999; Bernard et al., 2002; Kliem et al., 2008). The discrepancies between the reports most likely reflect variations in the NDF and starch intakes. In our study, the variations in the feeding regimens within the feeding systems may have influenced the fiber and starch intake and, thus, masked the differences in the milk composition.

Overall, the FA profile of the milk from the BP farms was different from those of the milks from the GS and MS farms, whereas the profiles were similar between the GS and MS farms. Although the proportion of BP in the feed was approximately $15 \%$ in this study, the FA profile of the milk exhibited the same trend as that observed in the controlled studies that used BP as a component of the feeds for lactating cows (Miyazawa et al., 2007). In contrast, previous direct (Shingfield et al., 2005; Nielsen et al., 2006) and indirect (Chilliard et al., 2000) comparisons have shown differences in the

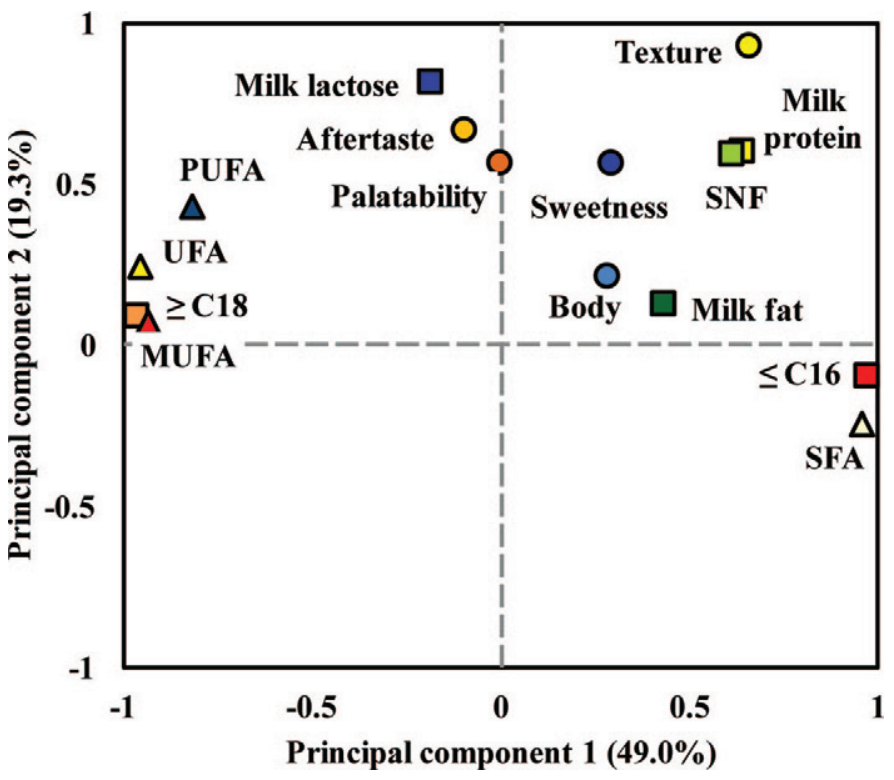

Figure 2. The principal component analysis describing the relationships among milk compositions and milk flavors. $\leq \mathrm{C} 16=$ sum of FA shorter than C16:1; $\geq \mathrm{C} 18=$ sum of FA longer than C18:0; SNF $=$ solids not fat: $\mathrm{SFA}=\Sigma \mathrm{C} 12: 0, \mathrm{C} 13: 0, \mathrm{C} 14: 0, \mathrm{C} 15: 0, \mathrm{C} 16: 0, \mathrm{C} 17: 0$, C18:0, C19:0, C20:0, and C22:0; MUFA $=\Sigma$ C14:1, C16:1, C16:1t, C18:1, C18:1t, and C20:1; PUFA $=\Sigma$ C18:2, C18:2t, C18:3, C20:3, and C20:4; UFA $=\Sigma$ MUFA and PUFA. $t=$ trans. Color version available in the online PDF. 
milk FA profiles of milks from cows fed GS and milks from cows fed MS. Milk from cows that were fed MS contained higher amounts of MUFA but lower amounts of $\leq \mathrm{C} 16$ compared with milk from cows fed GS. The inconsistencies between the results of these previous studies and our results may be attributed to the lower proportions of GS and MS in the diets of our study populations (approximately $22-32 \%$ in our study vs. $35-65 \%$ in previous studies).

The concentrations of $\leq \mathrm{C} 16$ and SFA were higher in the milk from the GS and MS farms than in the milk from the BP farms; however, the PCA showed that the proportion of MS in the diet was not related to the contents of these FA. Almost all of the C4:0 to C14:0 FA and approximately one-half of the C16:0 FA in milk are synthesized de novo in the mammary gland from acetate and BHBA originating from ruminal fermentation (Grummer, 1991; Chilliard et al., 2000). Further, fibrous feed types, such as GS and hay, promote acetic fermentation, whereas starchy feed types, such as maize and concentrates, lead to propionic fermentation in the rumen. In our study, both the GS and MS farms fed more forage to the cows than did the BP farms, resulting in a predominance of acetic fermentation in the rumen and the occurrence of active de novo synthesis in the mammary gland. However, MS is relatively rich in starch, and, consequently, it may not be possible to detect clear relationships between the proportion of MS and the contents of these FA. In contrast, the BP farms fed more concentrates to cows than did the other farms, suggesting that the rumens of cows on the BP farms presented a higher level of propionic fermentation. This increase in the level of propionic fermentation may reduce the flux of milk fat precursors to the mammary gland and limit de novo synthesis (Chilliard et al., 2000). Additionally, this explanation is also applicable to the results for the SFA, which are composed mainly of C12:0, C14:0, and C16:0 FA.

The concentrations of $\geq \mathrm{C} 18$ and UFA, including MUFA and PUFA, were higher in the milk from the BP farm than in the milk from the GS and MS farms. The PCA also showed a strong positive relationship between the proportions of $\mathrm{BP}$ in the diet and the levels of these FA. Fatty acid chains longer than C18 are derived from circulating blood lipids, which may originate from the digestion and absorption of dietary fat or from the mobilization of FA from adipose tissue (Grummer, 1991; Chilliard et al., 2000). Soybean curd residue and brewer's grain have relatively high crude fat contents (12.6 vs. 9.3\% DM basis, respectively; NARO, 2009), and both BP contain high levels of PUFA, typified by C18:2 and C18:3 (Abu-Ghazaleh et al., 2001; Peñalvo et al., 2004; Miyazawa et al., 2007). These observations suggest that the PUFA in the BP directly and indirectly increase the PUFA content of milk through biohydrogenation in the rumen. The milk from dairy cows fed a diet that included $9 \%$ brewer's grain contained more $\mathrm{C} 18$ and UFA than the milk from cows that were fed a diet that did not include brewer's grain (Miyazawa et al., 2007). Similarly, the levels of C18:0, C18:1 isomers, and C18:2 FA increased in the milk from cows supplemented with raw or extruded soybean (approximately $10-15 \%$ of the diet) relative to the levels in milk from cows that were fed a control diet (Chilliard and Ferlay, 2004). Thus, the addition of BP, such as soybean curd residue or brewer's grain, is an effective way to increase the MUFA and PUFA levels in milk, even in commercial situations.

The milk FA profiles were characterized by feeding system, but no significant differences in flavor were found between the milks from the different feeding systems. The lack of major differences in the sensory properties of milk observed in this study is similar to the results of previous studies, in which moderate changes in FA composition were achieved by feeding cows a diet rich in UFA (Aigster et al., 2000; Baer et al., 2001; Chen et al., 2004). The results of the present study may be attributed to the relatively low proportions of silage and BP in the diets and the large variations in the feeding regimens of the dairy farms. These complex but real-life conditions may obscure the flavor differences. Furthermore, esterified FA, which help determine the FA profile, are relatively inert in terms of flavor generation. Flavor-generating compounds, such as FFA, lactones, and ketones, are produced from esterified FA when milk is processed and heated (Urbach, 1990). Pasteurized milk is less processed than other dairy products. With little processing, it is difficult to produce the FFA or FA derivatives that underlie the unique flavors of milk, and, thus, we were not likely to find pronounced flavor differences. In addition, this study did not consider a panelist effect in the statistical analysis. Differences in the sensory response between panelists are important, and these differences are highly variable among untrained panelists and consumers (Drake, 2007). This statistical limitation might explain why no pronounced flavor differences were found among the milks. However, the body of the milk was slightly different between feeding systems, and this factor seems to be slightly associated with the milk fat content. Body, as known "koku" in Japan, is a complex property, and studies are currently being conducted to identify the substances in dairy products that are associated with body (Kobayashi et al., 2010). Milk flavor is a complex trait that is influenced by FA and their derivatives, fat globule size, and the concentrations of volatile compounds (Urbach, 1990; Nursten 1997). However, Dubroeucq et al. (2002) reported that 
the milk from cows fed exclusively grass silage ( $87 \%$ of the diet) had sensory properties that are distinct from those of the milk from cows fed exclusively MS ( $86 \%$ of the diet) (Chilliard and Ferlay, 2004). Therefore, more obvious differences, not only in the FA composition but also in the levels of other components, may be required to create a characteristic flavor and taste in milk.

The potential limitations of this study are the variability or complexity of the feeding regimens and the weak sensory testing. The variability and complexity of the feeding regimens used on commercial farms may be unavoidable because different farmers, even those in the same region, use different and often complex feeding strategies. A more detailed and controlled investigation is required to determine the influence of the feeding system on milk properties. In addition, the sensory evaluation requires a greater number of panelists because panelists vary considerably in age, product usage, geographical location, ethnicity, and nationality (Drake, 2007). In future studies, the sensory terms should be better defined when used in tests with consumers, and a descriptive sensory analysis should be performed by trained panelists.

\section{CONCLUSIONS}

Our results indicate that regional differences in feeding systems contribute to the differences in the FA compositions of milk produced by commercial dairy farms. However, the differences in the feeding systems did not influence the milk flavors that were analyzed in the study (i.e., sweetness, body, texture, aftertaste, and palatability). Other flavors, including more distinct flavors, should be analyzed in future studies. The daily feeding regimen is more or less the same among dairy farms and depends on which feed is the most economically feasible. However, if dairy farmers and the dairy industry wish to produce milks with region-specific flavors, the feeding systems must be further differentiated.

\section{ACKNOWLEDGMENTS}

We are grateful to K. Wada (Minorakunou Co. Ltd., Gifu, Japan) for assistance in dairy farm survey. We also thank dairy farmers and Gifu-ken Gyunyu yuso Co., a milk-shipping company, for their cooperation for our study.

\section{REFERENCES}

Abu-Ghazaleh, A. A., D. J. Schingoethe, and A. R. Hippen. 2001. Conjugated linoleic acid and other beneficial fatty acids in milk fat from cows fed soybean meal, fish meal, or both. J. Dairy Sci. 84:1845-1850.
Aigster, A., C. Sims, C. Staples, R. Schmidt, and S. F. O'Keefe. 2000. Comparison of cheeses made from milk having normal and high oleic fatty acid compositions. J. Food Sci. 65:920-924.

AOAC International. 2006. Official Methods of Analysis. 18th ed. AOAC International, Arlington, VA.

Baer, R. J., J. Ryali, D. J. Schingoeth, K. M. Kasperson, D. C. Donovan, A. R. Hippen, and S. T. Franklin. 2001. Composition and properties of milk and butter from cows fed fish oil. J. Dairy Sci. 84:345-353.

Bernard, J. K., J. W. West, and D. S. Trammell. 2002. Effect of replacing corn silage with annual ryegrass silage on nutrient digestibility, intake and milk yield for lactating dairy cows. J. Dairy Sci. 85:2277-2282.

Bugaud, C., S. Buchin, Y. Noël, L. Tessier, S. Pochet, B. Martin, and J. F. Chamba. 2001. Relationships between Abondance cheese texture, its composition and that of milk produced by cows grazing different types of pastures. Lait 81:593-607.

Carpino, S., J. Horne, C. Melilli, G. Licitra, D. M. Barbano, and P. J. Van Soest. 2004a. Contribution of native pasture to the sensory properties of Ragusano cheese. J. Dairy Sci. 87:308-315.

Carpino, S., S. Mallia, S. La Terra, C. Melilli, G. Licitra, T. E. Acree, D. M. Barbano, and P. J. Van Soest. 2004b. Composition and aroma compounds of Ragusano cheese: Native pasture and total mixed rations. J. Dairy Sci. 87:816-830.

Chen, S., G. Bobe, S. Zimmerman, E. G. Hammond, C. M. Luhman T. D. Boylston, A. E. Freeman, and D. C. Beitz. 2004. Physical and sensory properties of dairy products from cows with various milk fatty acid compositions. J. Agric. Food Chem. 52:3422-3428.

Chilliard, Y., and A. Ferlay. 2004. Dietary lipids and forages interactions on cow and goat milk fatty acid composition and sensory properties. Reprod. Nutr. Dev. 44:467-492.

Chilliard, Y., A. Ferlay, M. Mansbridge, and M. Doreau. 2000. Ruminant milk fat plasticity: Nutritional control of saturated, polyunsaturated, trans and conjugated fatty acids. Ann. Zootech. 49:181-205.

Croissant, A. E., S. P. Washburn, L. L. Dean, and M. A. Drake. 2007. Chemical properties and consumer perception of fluid milk from conventional and pasture-based production system. J. Dairy Sci. 90:4942-4953.

Drake, M. A. 2007. Sensory analysis of dairy foods. J. Dairy Sci. 90:4925-4937.

Dubois, M., K. A. Gilles, J. K. Hamilton, P. A. Rebers, and F. Smith. 1956. Colorimetric method for determination of sugars and related substances. Anal. Chem. 28:350-356.

Dubroeucq, H., B. Martin, A. Ferlay, P. H. Pradel, I. Verdier-metz, Y. Chlliard, J. Agabriel, and J. B. Coulon. 2002. L'alimentatuin des vaches est susceptible de modifier les caractéristiques sesorielles du lait. Renc. Rech. Ruminants. 9:351-354.

Feng, S., A. L. Lock, and P. C. Garnsworthy. 2004. A rapid separation method for determining fatty acid composition of milk. J. Dairy Sci. $87: 3785-3788$.

Fitzgerald, J. J., and J. J. Murphy. 1999. A comparison of low starch maize silage and grass silage and the effect of concentrate supplementation of the forages or inclusion of maize silage grain with the maize silage on milk production by dairy cows. Livest. Prod. Sci. 57:95-111.

Grummer, R. R. 1991. Effect of feed on the composition of milk fat. J. Dairy Sci. 74:3244-3257.

Japan Federation of Milk Processors Co-operatives. 2005. Sensory test method. Japan Federation of Milk Processors Co-operatives, Tokyo, Japan.

Japanese Industrial Standard Committee. 2004. JIS Z 8144: Sensory analysis-vocabulary. Japanese Standard Association, Tokyo, Japan.

Kliem, K. E., R. Morgan, D. J. Humphries, K. J. Shingfield, and D. I. Givens. 2008. Effect of replacing grass silage with maize silage in the diet on bovine milk fatty acid composition. Animal $2: 1850-1858$.

Kobayashi, N., S. Hachisuka, and O. Nishimura. 2010. Sensory structure on sweet cream Koku. Chem. Senses 35:J18. 
Marier, J. R., and M. Boulet. 1959. Direct analysis of lactose in milk and serum. J. Dairy Sci. 42:1390-1391.

Martin, B., A. Priolo, M. A. Valvo, D. Micol, and J. B. Coulon. 2005a. Effects of grass feeding on milk, cheese and meat sensory properties. Options Méditerr., Series A. 67:213-223.

Martin, B., I. Verdier-Metz, S. Buchin, C. Hurtaud, and J. B. Coulon. 2005b. How do the nature of forages and pasture diversity influence the sensory quality of dairy livestock products? Anim. Sci. $81: 205-212$

Miyazawa, K., H. Sultana, T. Hirata, S. Kanda, and H. Itabashi. 2007. Effect of brewer's grain on rumen fermentation, milk production and milk composition in lactating dairy cows. Anim. Sci. J. $78: 519-526$

NARO (National Agriculture and Food Research Organization). 2009. Standard tables of feed composition in Japan. Japan Livestock Industry Association, Tokyo, Japan.

Nielsen, T. S., E. M. Straarup, M. Vestergaard, and K. Sejrsen. 2006. Effect of silage type and concentrate level on conjugated linoleic acids, trans-C18:1 isomers and fat content in milk from dairy cows. Reprod. Nutr. Dev. 46:699-712.
Nursten, H. E. 1997. The flavor of milk and dairy products: I. Milk of different kinds, milk powder, butter and cream. Int. J. Dairy Technol. 50:48-56

Palmquist, D. L., A. D. Beaulieu, and D. M. Barbano. 1993. Feed and animal factors influencing milk fat composition. J. Dairy Sci. $76: 1753-1771$.

Peñalvo, J. L., M. C. Castilho, M. I. N. Silveira, M. C. Matallana, and M. E. Torija. 2004. Fatty acid profile of traditional soymilk. Eur. Food Res. Technol. 219:251-253.

Shingfield, K. J., C. K. Reynolds, B. Lupoli, V. Toivonen, M. P. Yurawecz, P. Delmonte, J. M. Grinari, A. S. Grandison, and D. E. Beever. 2005. Effect of forage type and proportion of concentrate in the diet on milk fatty acid composition in cows given sunflower oil and fish oil. Anim. Sci. 80:225-238.

Thomas, E. L. 1981. Trends in milk flavors. J. Dairy Sci. 64:10231027.

Urbach, G. 1990. Effect of feed on flavor in dairy foods. J. Dairy Sci. 73:3639-3650 